\title{
Health Expenditure Comparisons: Low, Middle and High Income Countries
}

Short running title: Health Expenditure Comparisons

\begin{abstract}
Cross-sectional health expenditure data are used to compare health expenditure aggregates and the contribution of the public and private sectors in a selection of 31 low, middle and high income countries. The comparative data illustrate the diversity of outcomes in terms of total health expenditure and its components even amongst countries with similar GDP per capita. Low and middle income countries on the whole, rely more heavily on private funding especially household out-of-pocket payments. Public funding is more prevalent for funding of curative care than for funding of pharmaceuticals in high, middle and low income countries. The results illustrate the usefulness of internationally comparable health expenditure data to undertake cross country comparisons. Such comparisons are crucial for contributing to evidence based policy.
\end{abstract}




\section{INTRODUCTION}

Expenditure on health care is an issue which dominates policy discussion at both the national and international level. International comparisons of health expenditure provide sound information which health policy makers can use to generate support for policy changes. This paper sets out to provide comparisons of health expenditure estimates for low, middle and high income countries which have been compiled using national health accounts data (NHA). Published comparisons of health expenditure are not common and this paper takes the comparisons further by using expenditure estimates for low, middle and high income countries [1, 2].

There is considerable variation in the organisation and financing of health care across countries and this is reflected in health expenditure comparisons [3]. This variation makes it essential that health expenditure aggregates are compiled nationally in a consistent and comparable manner. An international methodology for health expenditure compilation known as National Health Accounts (NHAs) has been developed by OECD and WHO to accommodate the differences in the organisation and financing and make comparisons more transparent and uniform.

Even with a common methodology, differences persist. For example, long term care in some countries is provided by hospitals, in some by residential care and some countries at home. These cross country differences in delivery of services make comparisons problematic. The limitations of the comparability of expenditure estimates in some dimensions may have an effect on the magnitude of total health spending (and consequently the share of GDP), the public-private share, as well as the breakdown by type of care and provider.

Ultimately, governments and policy makers would like to understand and measure the relationship between health care spending and health status, but answering this question is difficult for many reasons. Thus the objective of this paper is relatively modest. It is to examine aggregate health expenditure ratios and the components of health expenditure using cross sectional data from high, middle and low income countries.

\section{MATERIAL and METHODS}

Of all the health expenditure ratios, the most commonly used for comparisons is the ratio between current health expenditure and GDP. Interest in health expenditure ratios stems from a continuous drive for health system performance and cost containment at the same time. In most 
countries, a rise in the growth rate of health expenditure and of its share in GDP have been observed over time. Policy makers' interest in the changes have been driven largely by concerns of the implications of the growth for public expenditure.

Questions of the relationship between health expenditure and GDP have been debated over a long time period using many different techniques [4-6] Gerdtham and Jönsson [7] suggest that the studies can be grouped into two types. The first generation studies tended to use cross sectional data and to analyse cross country difference in health expenditures. One of the first of these types of studies by Newhouse, documented that GDP explains most of the variance in health expenditure between countries [8]. Thus with the evidence from the earlier studies, health care was termed a luxury good.

What Gerdtham and Jönsson term second generation studies use panel data and up-todate econometric techniques. These more recent analyses provide further confirmation of the observation that per capita GDP has a positive impact on health expenditure. The influence of other possible explanatory variables of relative prices, budget deficits and institutional factors is, at this point, not as conclusive.

The analysis of cross country health expenditure in the next section addresses a number of questions of policy importance for overall organisation of health care and its impact on health expenditure. The health expenditure data which are used for all countries is compiled using a methodology based on guidelines set out initially by the OECD [9] and the WHO [10] and thus are as comparable as possible. The analysis is based on the health expenditure data of 31 countries which have been chosen as they have produced consistent health accounts data for more than one time period ${ }^{1}$. Health accounts data were obtained from OECD and WHO WebPages [11, 12].

The 31 countries vary in terms of stage of economic development, size, region and most importantly for this analysis in the organisation and funding of their health systems. The most important difference in terms of the current analysis is the extent of the involvement of the private sector.

\footnotetext{
${ }^{1}$ Australia, Belgium, Canada, Czech Republic, Denmark, Finland, France, Germany, Hungary, Iceland, Japan, Korea, Netherlands, New Zealand, Norway, Poland, Portugal, Spain, Sweden and Switzerland are high income countries and members of the OECD whose data is internationally validated. The other countries are at different stages of NHA implementation and institutionalisation. Estonia and Slovenia are ascension countries of OECD and their NHA collection conforms to the international standards. Bangladesh, Chile, China, Malaysia, Philippines, Russia, South Africa, Sri Lanka and Thailand have all ongoing data collections at various stages of regularisation. Thus their health expenditure data are consistent with the international standards but are not necessarily compiled every year.
} 


\section{RESULTS}

\section{Health expenditure and GDP}

Figure 1 shows total per capita health expenditure for $2006^{2}$ expressed in World Bank international dollar rates ${ }^{3}$ and public and private expenditure as a percentage of GDP. Wide variation in overall health spending levels can be observed, ranging from Norway with total health spending per capita of 4521 in international dollar rates to the Bangladesh with total spending per capita of 39 in international dollar rates[13] .

Per capita expenditure shows the overall level of consumption of health goods and services by the population across the countries. The health spending to GDP ratio reflects a macro-economic approach, comparing the share of national income devoted to health care without any information on the absolute magnitude of these resources. One can get a sense of the relative magnitude of the health and economic resources, however by looking at the ratios for Norway (8.7\%), Denmark (9.5\%), Netherlands (9.3\%) and Sweden (8.9\%). Norway, in particular stands out in this group as a country with a low ratio for health expenditure, alongside high per capita health expenditure, indicating the relatively high level of GDP in that country. For Portugal (10\%), New Zealand (9.4\%) and South Africa (8.6\%), the reverse is true as the ratio is high but the per capita health expenditure is relatively low.

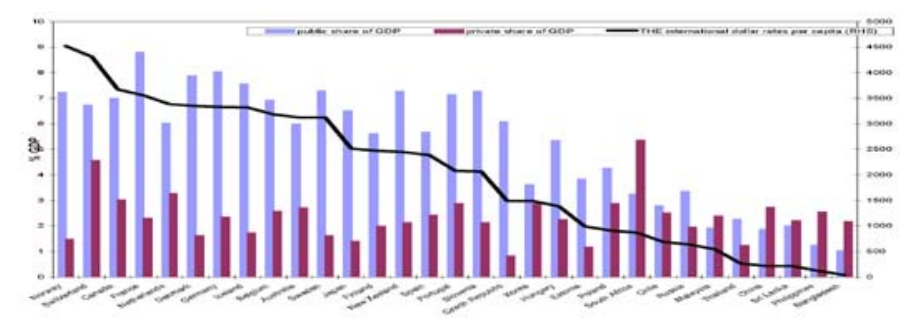

\footnotetext{
${ }^{2}$ Data for Australia, Japan, Sri Lanka, Sweden and Thailand are for 2005, for Bangladesh the data are for 2004.

3 Data are expressed in World Bank "international dollar" rates which provide a means of comparing spending between countries on a common base. An "international dollar" has the same purchasing power as an US\$ for total GDP in the US, but the purchasing power of the components are determined by the average international price structure, not the US price relatives.
} 
(Figure 1 here)

The observed differences in health spending per capita across countries are far greater than the differences in health expenditure ratios. Health expenditure per capita decreases from 4,521 in Norway to 39 in Bangladesh whereas the level of countries' national income devoted to health varied almost threefold from 3.2\% in Bangladesh to $11.3 \%$ in Switzerland. Health expenditure in high income countries is supported but not fully explained by a higher level of economic development. The relationship between GDP per capita and the share of GDP spent on health care may be influenced by institutional, cultural and economic factors such as provider payment methods, degree of universality of coverage, role of the private sector and relative prices. For example, despite Japan and Germany having the same GDP per capita, their health spending per capita differs considerably with Japan spending less than 75\% of the level of Germany on health. On the other hand, Netherlands, Denmark and Germany share borders and historical development in their health systems and have health expenditures per capita which are almost identical. The role and importance of a mixture of historical, socio-political and cultural phenomena in both levels and changes in health is still subject to debate as was mentioned earlier in the paper and summarised in Gerdtham and Jonsson [7]. There are some organisational forms and payments systems which seem to function well from an expenditure and health outcomes viewpoint in some countries such as GP gatekeeper arrangements, but there is no magic formula for health system design.

Figure 1 also shows the public and private health expenditure shares of the total. The average share for all 31 countries is $67.1 \%$ of per capita public health expenditure and $32.9 \%$ private expenditure. The OECD country average (including Estonia and Slovenia) is 74\% public and 26\% private. Public spending is significantly lower than the average in Switzerland, Korea and the Netherlands with less than $65 \%$ of spending publicly financed. At the other end of the scale around $88 \%$ of health spending is from the public purse in the Czech Republic. For the middle and low income countries, $48 \%$ of health expenditure is public and $52 \%$ is private. In China, the Philippines, South Africa and Bangladesh, more than $60 \%$ of spending is private.

\section{Households' out-of-pocket expenditure}


Private spending generally comes from 2 sources: private insurance and household outof-pocket expenditure ${ }^{4}$. Monitoring household out-of-pocket expenditure is vital from a health policy perspective to ensure that accessing health services does not financially impoverish households. Ideally it would be useful to track the burden of out-of-pocket payments on citizens with low incomes and those with poor health states. However, such monitoring requires household survey data and is not possible with more aggregated health expenditure estimates[14].

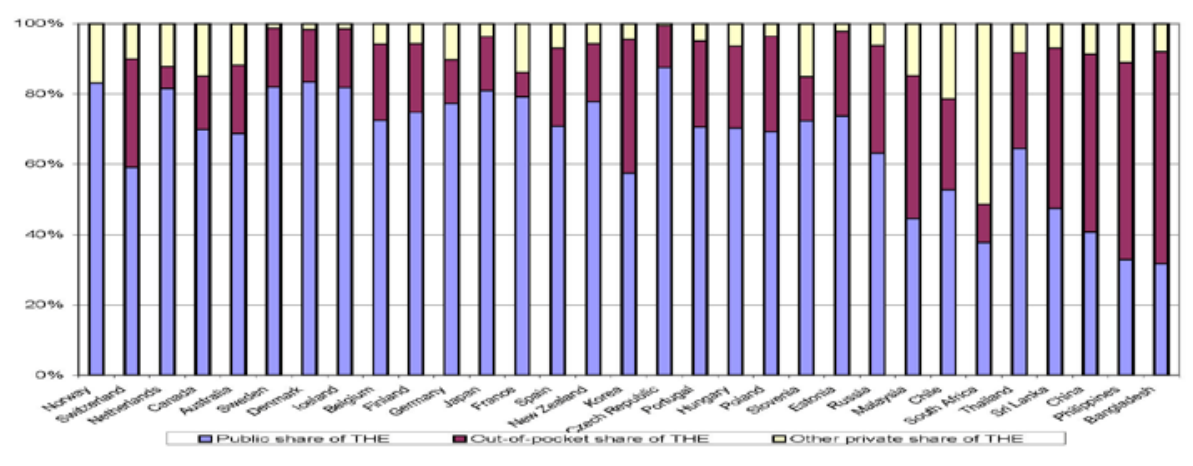

(Figure 2 here)

In Figure 2, the countries are arranged from left to right by GDP per capita. The figure shows clearly that on the whole countries with higher GDP per capita have higher proportions of total health expenditure financed from public sources. These countries by virtue of their high GDP per capita are more developed and have more sustainable public financing as a result of their more reliable revenue base. The reliability is the same whether countries rely on tax financed public insurance or payroll financed social insurance. There are exceptions: Switzerland and Korea have the lowest levels of public funding amongst the OECD countries of 59.1 and 57.5 percent and similar shares of total expenditure funded from out-of-pocket expenditure of 30.8 and 38 percent.

In light of continued cost pressures and strains on public finances, health systems across the OECD are striving to increase the value for money. The share of funding through private insurance may reflect health financing reform which has assigned a larger role to the private

\footnotetext{
${ }^{4}$ Private expenditure may also be funded by non-profit institutions serving households, corporations other than private health insurance and the rest of the world. Generally, the proportion that comes from these sources is minor.
} 
sector with the aim of meeting objectives of choice, increased efficiency and financial sustainability.

The six countries of Malaysia, Chile, South Africa, Sri Lanka, China and Philippines have the lowest shares of public spending with Philippines the lowest with 32.9\%. For OECD countries, the average percentage of public funding is 75\%. For non-OECD countries it is 53\%.

There is considerable variation in the arrangements for private financing across all countries. For example, the Czech Republic has private expenditure of $0.6 \%$ of total health expenditure, Thailand 8\%, Canada $14.9 \%$ and South Africa $51.4 \%$.

Out-of-pocket payments averaged $17.95 \%$ in the OECD countries and 34.9\% in the nonOECD countries. There is considerably less variability in the OECD data. The standard deviation of out-of pocket payment for the OECD countries is 8.7 compared with that for the non-OECD countries of 16.8. The percentage of health expenditure financing out-of-pocket ranges from $45 \%$ in Sri Lanka to 56\% in the Philippines and 60\% in Bangladesh.

Out-of-pocket payments are one of the most important components of health financing as they signal the extent of possible household catastrophic expenditures for health but are also the most difficult to estimate. Difficulties arise due to the necessity of compiling information from a number of sources, such as household expenditure surveys and provider records, which are of variable quality and availability.

Other private expenditure, largely private insurance premiums, also has the potential to restrict access and impoverish households. A number of the countries in Figure 2 have more expenditure on the other component of private expenditure than on out-of-pocket payments. In South Africa, the other component is more than $50 \%$ of the total, representing the importance of financing by private health insurance even though only approximately $20 \%$ of the population have private coverage. South Africa initially moved to regulate its long established private insurance industry in 1967, however, then deregulated it in 1989. The deregulation permitted risk rated rather than community rated premiums, effectively restricting access of high risk groups such as the aged to the private market or making the premiums very costly. Thus private insurance has the same capacity to impoverish households and restrict their access to needed care as out-of-pocket expenditure. Söderland and Hansl find that access to private health insurance cover in South Africa is strongly influenced by income[15]. 
Judging the impact of private payments on accessibility requires considerably more information than their share of total health expenditure. To assess whether out-of-pocket payments and other private expenditure contribute to impoverishing households requires information on at least, the distribution of private payments across income groups and the types of health goods and services being purchased. Health expenditure data have the capacity to shed light on the second issue but addressing the first requires access to micro data on health expenditures and household characteristics including income.

\section{Expenditure on types of health goods and services}

One of the most important questions to which consistent health expenditure estimates can provide an answer is: how is the purchase of types of health goods and services financed? Figure 3 shows the contribution of public expenditure to the main types of goods and services of curative and rehabilitative care and medical goods dispensed to outpatients. Under the NHA classifications, curative and rehabilitative care is a large category of care which covers all care under this type provided to inpatients, day case, outpatients and in the home. In practice rehabilitative care is difficult to distinguish from curative care and so most countries report the care under one category. Long-term care, ancillary services such as laboratory services and patient transport, pharmaceuticals administered in hospitals and public health services are excluded from curative and rehabilitative care.

The second health good and service classification shown in Figure 3 is medical goods dispensed to outpatients. This includes prescribed medicines, over-the-counter medicines and other medical non-durables. Generally, the largest component is prescribed medicines.

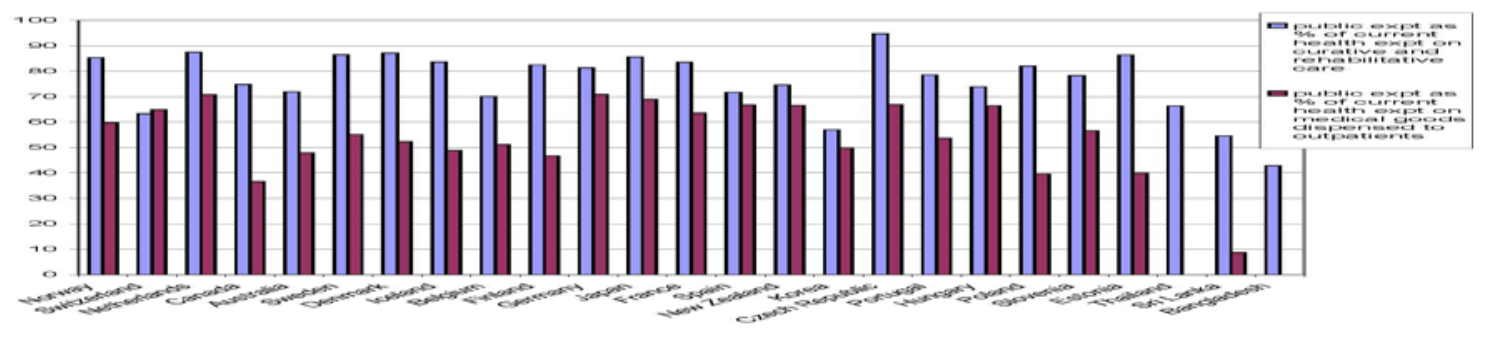

(Figure 3 here) 
The data in Figure 3 are based on a reduced sample of countries. The estimates of all the OECD and the two ascension countries to the OECD are still displayed in Figure 3. In addition, the estimates of Thailand, Sri Lanka and Bangladesh are shown. These 3 countries have publicly available and high quality country NHA reports [16-18].

The average public contribution to curative care for the $\mathrm{OECD}^{5}$ is $79 \%$ with a range from 95\% in the Czech Republic to 63\% in Switzerland. For the 3 middle and low income countries, the average is 55\%. For medical goods, the public contribution averages 57\% for the OECD countries with a range from $70 \%$ for Germany to $36 \%$ for Canada. The average for the 3 middle and low income countries is $2.9 \%$. The implications of the public funding depend very much on the extent of pooling in private funding. For example, Canada and France both have supplementary private insurance with significant reimbursement of the household contributions to pharmaceuticals. Australia has duplicative private insurance which subsidises households' access to private hospitals. In most low and middle income countries, the main source of private funding is household out-of-pocket payments (Figure 2). Even then the extent to which the out-of-pocket payment impoverish or inhibit households' access to care depends on the incidence of the spending. Sri Lanka for example has a $46 \%$ out-of-pocket share of total expenditure but also a commitment to ensure access of poor households to free inpatient services[19].

In Bangladesh, high out of pocket expenditure on purchase of pharmaceuticals has been a distinctive feature of household health expenditures over a long time period. The relatively low level of public funding combined with a small private insurance market has forced households to bear a very large proportion of national health expenditure through out-of-pocket payments.

The higher public contribution to curative care is in line with policy prescriptions of international agencies that governments should ensure access to a basic package of goods and services. For example, the WHO Strategy on Health Care Financing advises low and middle income countries to focus on a target of $30 \%$ of total health expenditure allocated to essential health services and primary health care but at the same time the countries should reduce the share of hospital based curative care and non-essential drugs in total health spending [20]. WHO also proposes a target of less than $30 \%$ on out-of-pocket payments for all member states.

\footnotetext{
${ }^{5}$ Includes Estonia and Slovenia.
} 


\section{DISCUSSION}

International comparisons of health expenditures are obviously of great interest to health policy-makers to monitor levels and changes of expenditure - both total and disaggregated against countries at both similar and different levels of development. Health systems in countries evolve with both changes in aggregate income and disease patterns[21]. Health expenditure in a country which is considerably higher than a similar economy indicates either that the health expenditure is too high, the economy against which one is comparing is spending too little or there are significant differences in the organisation of health care. All of these signal that cost containment or cost effectiveness tools may be applied fruitfully.

The figures in this paper highlight the heterogeneity of approaches used by all countries low, middle and high income - to fund their health care. The diversity of funding arrangements in high income countries has been well documented [22]. Most comparative research of health financing has concentrated on the OECD countries due to the availability of high quality and credible data in those countries. Macroeconometric studies on health and GDP, many of which were referenced earlier in this paper, similarly have concentrated on OECD countries. Thus the detailed analyses of OECD countries' funding arrangements allows us to draw some lessons for low and middle income countries.

Public policy is the primary determinant of the role and size of public and private funding of health. Governments in low, middle and high income countries all look to private health insurance as a means to address some health system challenges. In high income countries, public financing of health tends to be substantial but many of these countries have well-developed private insurance schemes. Switzerland and Korea are exceptional amongst high income countries in having private sectors greater than $40 \%$ of the total. The Czech Republic, Japan, Norway, Poland and Spain have private insurance schemes but with a negligible share of total financing.

Motivations for establishing private health insurance in high income countries are varied, but in general the benefits of private insurance include responsiveness and choice for consumers of health care services as well as injection of more resources into health. Private insurance may duplicate, complement and/or supplement the coverage of public insurance. Private insurance may be associated with equity challenges due to the accessibility of insurance products across income groups and claims that private insurance contributes to total cost escalation. Countries such as Switzerland, Germany and France with significant private health insurance markets also tend to 
have high expenditure per capita (Figure1). The United States also falls into this category but is not included in our sample due to data difficulties [22]. The relationship between private health insurance and out-of-pocket payments is of utmost importance to all countries but is largely unresolved.

Middle income countries such as Chile, Malaysia, South Africa and Thailand have diverse funding arrangements as they move closer to $100 \%$ coverage and more public financing. It is apparent that low and middle income countries due to their low sustainability of government expenditure rely more on private financing, either private insurance or donor funding, than the high income countries. An exception is Thailand which created the 30-Baht-scheme for lower socio-economic groups in 1999 to provide coverage for 40\% of the Thai population who were uninsured.

Chile has experienced rapid growth in GDP over the last 20 years. It has a modest share of GDP devoted to health services of 5.3\% (Figure 1) yet very good population health outcomes [23]. South Africa has a similar GDP per capita but a much higher proportion of GDP devoted to health expenditure of $8.6 \%$.

The high share of GDP expenditure on health and the development of private insurance in South Africa provides salutary lessons for middle and low income countries. The South African economy and population have recently experienced the devastating impact of HIV and AIDS. This combined with inequalities in income distribution and access to social services has resulted in poor population health outcomes in spite of a high share of GDP devoted to health for a middle income country. Furthermore, private health insurance provides $51.4 \%$ of the health funding in South Africa but covers only $20 \%$ of the population; further emphasising the pressures of inequalities in access. Low and middle income citizens in South Africa who access the public system have a perception that they are being provided with care of inferior quality to that of the private sector.

South Africa shares a long standing history of private health insurance with Australia, the Netherlands and France [15]. Unlike South Africa, the governments of the other countries have quite recently taken a more active role in health financing. In Australia for example, public health insurance was first introduced in the 1970s.

Malaysia is a middle income country with a profile of public and private funding which is similar to that of low income countries (Figure 2). It has, for example, a public expenditure share 
of total health expenditure which is less than $50 \%$ and out-of-pocket expenses at $40.5 \%$ of the total. Malaysia is a Federation of a number of states and has only recently developed a national mechanism for financing health care, after several attempts to do so[24]. In recent years, there have been substantial increases in the public budget into health care. An ongoing health financing challenge in Malaysia which has implications for other middle and low income countries is the geographical maldistribution of services. The lack of health facilities in some remote areas, limiting access to health services, implies that for people in remote and underresourced areas catastrophic health expenditure is not a problem as this is only observed when households need and use health services [25].

Low income countries such as Sri Lanka and Philippines have less reliable collection of tax revenue and subsequent low government expenditure in health and other social expenditures. All low income countries in Figure 2 have public funding which is less than $50 \%$ of the total, relatively minor funding by private insurance and high levels of out-of-pocket payments. Many low income countries rely on donor funding and provision of services by faith-based charities. The key to improving the public insurance coverage is improvement in the tax revenue base which accompanies economic growth. During the transition to higher growth, governments of low income countries can do much to protect the poor from catastrophic health expenditures by ensuring that out-of-pocket payments are not imposed on access to essential health services. For this reason, it is desirable that health expenditure ratios be assessed against population health outcome indicators such as the infant mortality rate.

International comparisons have underpinned a huge area of research enquiry into the relationship between health expenditure and GDP and the relationship between public expenditure and total health expenditure. At this stage, much of this literature has been somewhat inconclusive. All of this points to the need for better quality data and an empirical framework which accounts for more variables. NHA data can fill this gap. Health estimates based on NHA have been particularly influential in analyses of health financing as an estimate is made of both public and private expenditure. Without NHA data, countries can reasonably estimate public expenditure but private expenditure is either omitted or based on an informed guess. A recent IMF report acknowledges the importance of NHA data for providing comprehensive and comparable data on total health expenditure in low, middle and high income countries[21]. 
This paper covers a small part of the story on the macroeconomics of health financing. While much work has been undertaken on the macroeconometrics of health expenditure, the macroeconomic framework is still relatively underdeveloped [7]. Issues such as how health expenditure outcomes impact on the macroeconomy and vice versa, are largely unexplored. We know for example that good health is a key ingredient for productivity improvements but we do not know the impact of good health and labour force status on other macroeconomic variables such as the saving rate. Closer to the emphasis in this paper, the financing mix of the health sector is likely to have a direct impact on the macroeconomic variables of tax, the budget deficit and the saving rate.

The global financial crisis of 2008 and 2009 has highlighted the significance of the relationship between economic growth rates and government expenditure, generally and public health expenditure in particular. This recent downturn has emphasised the usefulness of a macroeconomic analysis of health finance and a systematic approach to development of the evidence-base for policy. Governments and international agencies are increasingly aware of the importance of maintaining levels of health and welfare expenditure during a time when unemployment and poverty rates are increasing. A recent OECD publication noted that when GDP growth slowed recently, public health expenditures continued to rise leading to an increase in the ratio of health expenditure to GDP in many countries [26].

\section{CONCLUSIONS}

The analysis in this paper of components of health expenditure for low, middle and high income countries shows that, in general, low income countries spend proportionately less on health, they have proportionately less public funding, private insurance plays a minor role and household out-of-pocket payments are a higher proportion of the total than in middle and high income economies. As countries become more developed and wealthier, they devote more public resources to health and spend proportionately more on health per capita. These results are in general agreement with all studies[21]; however variation of health expenditure from the norm is encountered with differences in institutional development. South Africa is an example of this with its well established private insurance industry.

Health expenditure data offer a consistent framework for measurement both across time and countries with a capacity to address questions of the relationship between health expenditure 
and its components and GDP. The more difficult and arguably more substantive questions cannot be addressed adequately using aggregate expenditure data. These questions include issues of efficiency, equity, quality and appropriateness of care. 


\section{REFERENCES}

1. Orosz E, Morgan D. SHA-Based National Health Accounts in thirteen OECD Countries: a comparative analysis. Paris: OECD2004 Contract No.: 16.

2. Heijink R, Noethen M, Renaud T, Koopmanschap M, Polder J. Cost of illness: An international comparison Australia, Canada, France, Germany and The Netherlands. Health Policy. 2008;88(1):49-61.

3. McGuire A, Parkin D, Hughes D, Gerard K. Econometric Analyses of National Health expenditures: Can Positive Economics Help to answer Normative Questions? Health Economics. 1993;2:113-26.

4. MacDonald G, Hopkins S. Unit Root Properties of OECD Health Care Expenditure and GDP Data. Health Economics Letters. 2002;6(1):3-8.

5. Hansen P, King A. The determinants of health care expenditure: a cointegration approach. Journal of Health Economics. 1996;15:127-37.

6. Carrion-i-Silvestre JL. Health care expenditure and GDP: Are they broken stationary? Journal of Health Economics. 2005;24:839-54.

7. Gerdtham U-G, Jonsson B. International Comparisons of Health Expenditure. In: Culyer AJ, Newhouse JP, editors. Handbook of Health Economics. Amsterdam: Elsevier; 2000.

8. Newhouse AJ. Medical care expenditure: a cross-national survey. Journal of Human Resources. 1977;12:115-25.

9. $\quad$ OECD. A System of Health Accounts OECD OECD, editor: OECD; 2000.

10. World Health Organization, World Bank, USAID. Guide to producing national health accounts with special applications for low-income and middle-income countries. World Health Organization, editor. Geneva: World Health Organization; 2003.

11. OECD. OECD.stat. OECD; 2009 [14th August 2009]; Available from:

http://stats.oecd.org/index.aspx?r=786435.

12. World Health Organization. WHO National Health Accounts Country Information. WHO; 2009 [cited 200911 June 2009]; Available from: http://www.who.int/nha/country/en/.

13. World Bank. World Bank Statistical Manual International Comparisons of Income. World Bank Group; 2009 [17th August 2009]; Available from:

http://web.worldbank.org/WBSITE/EXTERNAL/DATASTATISTICS/EXTDECSTAMAN/0,,contentMD K:20915418 menuPK:2648194 pagePK:64168445 piPK:64168309 theSitePK:2077967,00.html.

14. Murray CJL, Xu K, Klavus J, Kawabata K, Hanvoravongchai P, Zeramdini R, et al. Assessing the Distribution of Household Financial Contributions to the

Health System: Concepts and Empirical Application In: Murray CJL, Evans DB, editors. Health Systems Performance Assessment: Debates, Methods and Empiricism. Geneva: WHO; 2003.

15. Söderland N, Hansl B. Health Insurance in South Africa: an empirical analysis of trends in risk pooling and efficiency following deregulation. Health Policy and Planning. 2000;15(4):378-85.

16. Rabbani G, Hossain N. SHA-Based Health Accounts in the Asia/Pacific Region: Bangladesh 2006: OECD2007.

17. Tisayaticom K, Patcharanarumol W, Tangcharoensathien V, Tiampriwan A, Sumalee H. SHABased Health Accounts in the Asia/Pacific Region: Thailand 2005: OECD2007.

18. Fernando T, Rannan-Eliya RP, Jayasundara J. SHA-Based Health Accounts in the Asia/Pacific Region: Sri Lanka 1990-2004: OECD2007.

19. Rannan-Eliya R, Sikurajapathy L. Sri Lanka: "Good Practice" in Expanding Health Care Coverage. Colombo: Institute for Health Policy2009.

20. World Health Organization Western Pacific Region and South-East Asia Region. Strategy on Health Care Financing for Countries of the Western Pacific and South-East Asia Regions (20062010)2005.

21. Hsiao W, Heller PS. What should macroeconomists know about health care policy?: IMF2007 Contract No.: WP/07/13. 
22. Tapay N, Colombo F. Private Health Insurance in OECD Countries: The Benefits and Costs for Individuals and Health Systems. In: OECD Health project, editor. Towards High Performing Health Systems. Paris: OECD; 2004.

23. Coustasse A, Hilsenrath P, Rojas PS. The case of South African and Chilean Health Systems: Comparison of Financial, Economic and Health Indicators. The Internet Journal of World Health and Societal Politics. 2005;2(2).

24. Barraclough S. The Politics of Privatization in the Malaysian Health Care System. Contemporary Southeast Asia. 2000;22(2):340-59.

25. Kawabata K, Xu K, Carrin G. Preventing impoverishment through protection against catastrophic health expenditure Bulletin of the World Health Organization. 2002;80(8):612.

26. OECD. Health Update. Paris: OECD2009 July. 